\title{
A Review on the Study of the Generation of (Nano)particles Aerosols during the Mechanical Solicitation of Materials
}

\author{
Neeraj Shandilya, ${ }^{1,2}$ Olivier Le Bihan, ${ }^{1}$ and Martin Morgeneyer ${ }^{2}$ \\ ${ }^{1}$ DRC/CARA/NOVA, Institut National de l'Environnement Industriel et des Risques (INERIS), \\ Parc Technologique Alata BP 2, 60550 Verneuil-en-Halatte, France \\ ${ }^{2}$ Université de Technologie de Compiègne (UTC), rue Roger Coutollenc, 60200 Compiègne, France \\ Correspondence should be addressed to Neeraj Shandilya; neeraj.shandilya@utc.fr
}

Received 26 April 2013; Accepted 17 December 2013; Published 27 January 2014

Academic Editor: Yanbao Zhao

\begin{abstract}
Copyright (C) 2014 Neeraj Shandilya et al. This is an open access article distributed under the Creative Commons Attribution License, which permits unrestricted use, distribution, and reproduction in any medium, provided the original work is properly cited.

This paper focuses on presenting the forefront of the interdisciplinary studies conceived towards the generation of the wear particles aerosol when materials are subjected to mechanical stresses. Various wear mechanisms and instrumentation involved during stress application and aerosolization of wear particles, as well as particles characterization, measurement, and modeling techniques are presented through the investigation of a series of contextual works which are emphasized on the identification of these aspects. The review is motivated from the fact that understanding mechanisms involved in wear-induced particle generation, both at nanoand at microscale, is important for many applications that involve surfaces sliding over each other due to various potential health aspects. An attempt has been made to explain how the information based on this broad spectrum of subjects discovered in this contribution can be used and improved in order to produce a more resilient, rational, and versatile knowledge base which has been found lacking in the present literature during its survey. The area of study is highly multidisciplinary since it involves aerosol, particle, and material sciences.
\end{abstract}

\section{The Problem Formulation}

Advances in nanotechnology are driven by rapid commercialization of products containing nanomaterials with remarkable properties. This is reflected in the enormous number of publications on nanotechnology. These nanomaterials may have a tendency to get released in air in the form of particle aerosol. Particle aerosol is the suspension of solid or liquid particles in the gaseous medium. It is generally formed by the disintegration of liquids or solids into finer constituents. In [1], authors have explained comprehensively how the particles, after being generated, get suspended in air to form an aerosol along with the behavior associated with their different structures. Various physical phenomena (e.g., dispersion, coagulation, sedimentation, etc.) are also explained which guide their size evolution. When the number of publications on characterization of this particle aerosol in the workplaces was enquired through the means of this study, it was found that it is comparatively much smaller. In spite of this, the fact cannot be denied that the overwhelming use of manufactured nanomaterials (MNM) in contemporary applications has brought potential risks to the workers and consumers due to their release in air during their use. Upon exposure, these nanomaterials may interact with human organism through inhalation or dermal contacts and get deposited inside the body. In fact, their interaction modes with human body and potential hazards associated with them form the basis of another newly emerging field of study called nanotoxicology $[2,3]$. This problem has now started getting attention by the researchers and has been highlighted recently by various research units throughout the world. In one of these researches on industrial production and professional application of manufactured nanomaterialsenabled end products in Dutch industries [4], the researchers have found that $76 \%$ of the companies, having potential risks related to working with MNM, do not have a specific point of interest towards the exposure controls, thus demonstrating a lack of awareness. The total number of workers potentially 
exposed to MNM during the production or application of MNM-enabled end products is estimated to be approximately 3,000 in The Netherlands. A literature review by European Agency for Safety and Health at Work (EU-OSHA) on workplace exposure to nanoparticles [5], has mentioned that the available information on the generation and measurement technology of the nanomaterials at workplaces is currently superficial. During another study on the sources of generation of nanoparticles aerosols, [6] has realized the lack of a "rational science-based approach" to minimize their generation and supported the continued study with appropriate industrial development. The Scientific Committee on Emerging and Newly Identified Health Risks (SCENIHR) [7] has stressed in a scientific report on an approach of case by case basis for the assessment of nanoparticles presence. Insufficient knowledge and data concerning nanoparticles characterization and their detection and measurement have also been indicated. The research report by "L'Institut de Recherche Robert-Sauvé en Santé et en Sécurité du Travail" (IRSST) [8] favors a preventive approach aimed at minimizing occupational exposure to nanoparticles when their risk assessment cannot be established precisely. They propose a step-by-step approach, followed by some examples of applications in industry or research. In a document issued by National Institute for Occupational Safety and Health (NIOSH) and Centers for Disease Control and Prevention (CDC) on the approaches to safe nanotechnology [9], the authors have identified workplace tasks in which there is a huge risk of exposure to nanomaterials. Some of them are generation of nanoparticles in nonenclosed systems; handling tasks (weighing, blending, spraying, etc.) of nanomaterials; maintenance on equipment and processes used to produce or fabricate nanomaterials and the cleaning-up of spills and waste material containing nanomaterials; and cleaning of dust collection systems used to capture nanoparticles; machining, sanding, drilling, or other mechanical disruptions of materials containing nanoparticles. One should note that all these activities involve the application of stresses on a surface.

From the outcomes of aforementioned researches or surveys, it is clear that the manufactured nanomaterials may pose a serious problem if not assessed properly. Their generation and characterization techniques are still underdeveloped. Therefore, this work presents a state of the art of such an aspect. It focuses on the works that may contribute towards the development of a base explaining the (nano)particle release mechanisms and principles conceived up to date. It further discusses the methods being adopted towards the study of their release, characterization, and modeling. This paper targets all the stakeholders associated with production or processing or use of nanomaterials-academicians, industries, and government research organizations. The paper is organized as follows. Section 2 deals with the experimental state of the present knowledge, thereby presenting different solicitation methods and characterization techniques; Section 3 structures the theoretical base present which could prove to be useful while modeling; Section 4 discusses various outcomes of this study and projects a prospective direction towards the improvement of the knowledge base on the (nano)particles release. An annexure is also provided which further elaborates the description of the instruments that have been used to provide solicitation and have been mentioned in Section 2. The authors have tried to present an exhaustive image of the state of the art as far as possible but further suggestions from readers towards its improvement would be welcomed.

\section{Experimental State}

2.1. Contextual Tribological Studies Conceived. The study of the wear mechanisms started with the study of the development of the force of friction during a relative displacement between two surfaces. It has been carefully discussed how a consideration of the deformation of the two bodies may be used to explain friction [18]. Bowden and Tabor have shown that the interaction between the two bodies in the area of contact, where they come very close together on an atomic scale, is so strong that the application of a tangential force tending to slide two normally loaded bodies over each other nearly always produces deformation and wear in the bodies themselves, rather than slip in the original interface. The process of continuous sliding theoretically has been examined and showed the importance of the strength of the surface interaction [19]. Verkhovskii seems to have been the first to point out that very high pressures would occur in the small regions of contact of rough bodies and that these regions would therefore be in a wear state. The contact of the rough bodies at atomic scale can be understood better if the surfaces are considered to be composed of asperities. The generation of the particles can be directly associated with the rupture of these asperities. The asperities have been used to explain a critical limit of the load existing during the abrasion of two bodies [20]. If the load increases above this critical limit, the softer material of the two sliding bodies would experience continuous incremental deformation and hence wearing starts.

This critical limit was further investigated by assuming two particular geometries for asperities: spherically tipped and cylindrical [20]. They found that the critical limit can be influenced by the machining processes used to prepare the harder surface, at least in so far that this leaves its mark on the surface topography. However, such a shape assumption for the asperities yields an isotropic deformation of the asperities because of their symmetrical shape. Considering an anisotropic deformation of the asperities, [21] presented a unique study for a microslip between a flat smooth surface and a flat rough surface covered with uniformly distributed ellipsoidal elastic bodies. Microslip is a small relative tangential displacement in a contacting area at an interface when the remainder of the interface in the contacting area is not relatively displaced tangentially [22]. Reference [23] presented the concept of input wear energy during the subjection of a material to mechanical stresses which they demonstrated to be proportional to the number of released aerosols of wear particles.

There have been three wear mechanisms explained and considered to be responsible for material removal during abrasion: ploughing, cutting, and wedge formation [24]. 
These mechanisms were shown to be functions of degree of penetration of one body inside the other, which in turn depends on the normal load, true area of contact, and the hardness of two materials: $D_{p}=R\left(\pi H_{v} / 2 W\right)^{1 / 2}-$ $\left(\left(\pi H_{v} / 2 W\right) R^{2}-1\right)^{1 / 2}$, where $D_{p}$ is the degree of penetration, $R$ is the radius of the tip of the penetrator, $H_{v}$ is the hardness of the specimen, and $W$ is the normal load.

2.2. Identification of Solicitation Methods Used. A material starts wearing when it is exposed to a certain degree of solicitation which can be done in a number of forms: mechanical, thermal, UV, stress, and so forth. The solicitation methods can be broadly classified in two categories: high energy and low energy input.

2.2.1. High Energy Input. In this category, range of mechanical devices can be included which operate on high transmission power and thus high input and output. This includes grinders and sanders. These types of devices are mainly used in the material processing sites. A review of various significant solicitation studies has already been shown in [23]. In the present work, the studies which remained excluded, but inevitable, are mentioned. While grinding beryllium ceramic, [25] found a domination of the particles $<100 \mathrm{~nm}$ in the number weighted aerosol size distribution generated. Reference [26] has demonstrated that dry paint scrapping and sanding can lead to substantial particle number concentrations below $1 \mu \mathrm{m}$. Reference [10] used high speed grinding to verify the mechanical generation of ultrafine aerosol particles. They found a particle size range of $4.22 \mathrm{~nm}$ to $20.5 \mu \mathrm{m}$. The substrates selected for the study were steel, aluminum, PTFE, hardwood, granite, and clay ceramic. They concluded that the ultrafine particles do have the potential to form a significant component of a grinding aerosol for a number of substrates. Reference [11] used an abrasion process for applying the mechanical stress on the surface of a cotton fabric sample covered with silica nanoparticles. Reference [27] investigated the potential size distributions of sanding dust released from paints produced with and without nanoparticles. Dust emissions from sanding generated the particles in various size modes in which the number concentrations varied considerably in between the nanoparticles doped and reference paint. Reference [12] subjected a semimetallic brake lining to full scale automotive brake dynamometer tests. They found that the released wear debris has different sizes and shapes at different values of applied pressure, sliding velocity, and temperature. Reference [28] reported 35\% of the wear debris to be airborne while [29] reported it up to $50 \%$.

References $[13,14,30,31]$ investigated the wear resistance of the components using Taber test. The primary measurement result was the mass loss which is a measure of the wear resistance. Reference [31] compared the wear resistance of the cutting tools for an interrupted cut machine by means of Taber test. Reference [13] developed a sensitive test method for the quantification of the particle release from coated surfaces into air by a defined stress, comparable to the domestic use. However, the total number of generated submicronic or nanoparticles was extremely low and lies below the statistic significance threshold. During the abrasion of an epoxy-carbon nanotube nanocomposite [14], the measured particle concentrations of the particles lying between $20 \mathrm{~nm}$ and $800 \mathrm{~nm}$ were between 8000 and 20000 particles $/ \mathrm{cm}^{3}$, whereas. [32] emphasized on the design of nanocomposites with $\mathrm{SiO}_{2}$ and $\mathrm{TiO}_{2}$ nanoparticles for the hazard reduction extending to the full nanocomposite life cycle. It has been pointed out by $[33,34]$ that, if $\mathrm{TiO}_{2}$ nanoparticles are used in nanocomposites with organic polymers, there can be a substantial increase in the degradability under solar or UV irradiation. Thermal degradation may also be enhanced by the incorporation of nanoparticles. Reference [35] provided evidence that $\mathrm{TiO}_{2}$ nanoparticles used in polymeric wall paints are detached from new and aged facade paints by natural weathering. Reference [15] studied the effect of Taber abrasing, sanding, and UV radiations on the thermoplastic and cementitious nanocomposite materials. They confirmed the phenomenon of chalking, that is, release of pigments from weathered paints from the thermoplastic composites under the UV radiations. In a similar work [36], release of free CNTs was not detected under any condition using several detection methods during the abrasion and machining of a CNT-TPU composite. During their study of nanoparticle emission of $\mathrm{TiO}_{2}$ nanopowder coated on different substrates including wood, polymer, and tile, [37] found that the tile coated with $\mathrm{TiO}_{2}$ nanopowder produces highest particle emission (no. $22 / \mathrm{cm}^{3}$ at $55 \mathrm{~nm}$ ) due to nanopowder separation during the simulation process done by using a UV light, a fan, and a rubber knife in order to simulate the sun light, wind, and human contacting conditions. Also, the UV light was shown to increase the release of particle below $200 \mathrm{~nm}$ from $\mathrm{TiO}_{2}$ nanopowder coating materials. Reference [38] reported the influence of nanoclay on mechanical drilling of PA6 composites, in terms of dust generation. They found a total particle concentration of $20,000 \mathrm{~cm}^{-3}$ over a particle size range of 5 to $512 \mathrm{~nm}$. During a sanding test of a nanocoated piston cap, [23] found that the total number concentration of the released particles was dominated by the nanoparticles with a mean diameter size of $35 \mathrm{~nm}$. This finding was found to be coherent with [27] and Göhler et al. [39].

2.2.2. Handling. The handling of materials, that is, storing, conveying, filling, and mixing, leads to dust liberation. This capability of generating dust is described as dustiness. This type of release of particles is characterized by low energy input. However, the multitude of dust generation varies from process to process. For example the particle generation associated with daily activities of solid material handling may differ from handling of disperse particle systems. Reference [23] demonstrated an insignificant particle release [40] during the conventional handling operations like extraction of a part from its bag, bag agitation, displacement of the part with some small physical impacts, and rubbing with gloves. On the contrary, the dust liberation property of disperse particle systems depends on a multitude of variables and also on the method and intensity of stressing. During an investigation of $\mathrm{TiO}_{2}$ and $\mathrm{SiO}_{2}$ powders in free drop conditions, [41] demonstrated a release of nanoparticles of $10 \mathrm{mg} / \mathrm{m}^{3}$ and $40 \mathrm{mg} / \mathrm{m}^{3}$ for $\mathrm{TiO}_{2}$ and $\mathrm{SiO}_{2}$, respectively. The SWCNT agitating principle of $[42,43]$ in a centrifuge tube has also 
been used by [44] to characterize the amount, particle size distribution, and morphology from different nanostructured powders including $\mathrm{TiO}_{2}$ and $\mathrm{ZnO}$ and carbon materials like SWCNT, MWCNT, and fullerenes. To improve the aerosolization process of CNTs, [45] agitated the sieve plate of the fluidized bed by a shaker. The results showed a considerable release of CNTs with material specific fractions of particles/agglomerates in the nanometer size range.

\subsection{Characterization}

2.3.1. Mass or Number Characterization. Mass or number characterization means the characterization of the particles release in terms of their number or mass. Such characterization techniques require the detection of the particle concentration and the number size distribution. Reference [46] has already presented a comprehensive list of various existing measurement and sampling devices for airborne nanoscale materials used in workplace exposure studies. In order to present a state of the art of this aspect, Table 1 presents some of the techniques which are at the instrumentation forefront. Reference [47] did an investigation on the production of dust by hand sanders when used without dust extraction, with integral dust extraction, and with external dust extraction. The apparatus used for the measurement was designed to carry out sanding in a repeatable manner, simulating normal working practice. The first well-recognized study on the particles size distributions of airborne particles released during the machining of the materials was done by [10]. As demonstrated by Figure 1, they characterized the particles size distribution over particles sizes ranging from $4.2 \mathrm{~nm}$ to $20.5 \mu \mathrm{m}$, produced from the high speed grinding of a variety of materials, by using a Condensation Particle Counter (CPC 3022A TSI) Scanning Mobility Particle Sizer (SMPS) in conjunction with a Differential Mobility Analyzer (DMA 3085 TSI), and Aerodynamic Particle Sizer (APS 3320 TSI). Prior to feeding these instruments, the flow was being passed through a stainless steel chamber acting as an emission chamber [48] for background particles free air. Reference [27] investigated the particle size distributions of sanding dust released from paints produced with and without engineered nanoparticles. They characterized the emitted particles in terms of number size distribution as well as surface area and mass size distribution. The particle size distribution was measured from the chamber using an APS Model 3321 TSI, a TS1 diluter model 3302A due to high particle concentrations, and a Fast Scanning Mobility Sizer (FMPS 3091 TSI). Reference [11] used SMPS Grimm 5.5-300 and CPC Grimm 5.403 to characterize the concentration and number size distribution for the nanoparticles emitted during the Taber abrasion of a fabric piece made of a PET layer coated with an additional PVC layer containing nanoclays.

Figure 2 shows their findings. Reference [13] combined the methodology adopted by [11] for abrasion and [10] for the characterization of the particles released during the abrasion of the fiberboard surfaces coated with two different mixed batches polyurethane. A similar approach was again adopted during the Taber abrasion of epoxy-carbon nanotube nanocomposites [14].
It is worth mentioning that the present work does not include the studies which have been discussed in [23]. Therefore, the readers are encouraged to refer the same [23] in order to have more comprehensive idea.

2.3.2. Microscopy. The microscopy of the particle released during the solicitation process can be done offline by capturing and collecting them for analysis, that is, sampling [49]. Microscopic analysis may help in determining the state of existence of the particles in air when released from the surface which may be agglomeration or dispersion. Morphology of the particles can also be observed directly which may further help in controlling the solicitation parameters according to the intended morphology of the particles. If the solicitation of a two-phase material (composites, etc.) has been done, such an analysis can verify the tendency of the released particles to remain embedded or exist in free state. Such tasks are normally accompanied using transmission electron microscopy (TEM). As far as the analysis of various surface phenomena is concerned, it can be done by using atomic force microscope (AFM), scanning electron microscope (SEM), and profilometer. However, these techniques can be roughly divided in two categories: high and ultrahigh resolution. High resolution techniques involve SEM, TEM, and profilometry, whereas AFM is involved in the applications where ultrahigh resolution of a surface is required.

High Resolution. Many wear related phenomena have been explained on the basis of the microscopic observations of the worn surfaces and wear particles. Figure 3(a) shows TEM micrograph of wear debris of a semimetallic polymer matrix composite brake material generated by a dynamometer [12], whereas Figure 3(b) shows the SEM image of ball-milled sample of the same material.

Figures 3(a), 3(b), and 4 directly demonstrate the effect of temperature and stresses during the two processes as the morphology of ball-milled sample differs from wear debris collected in dynamometer. The TEM image (Figure 4) shows the resulting wear particles obtained during [13] the Taber abrasion of a steel panel embedding zinc oxide particles. It is shown that the particles $<100 \mathrm{~nm}$ remain embedded in the coarse wear particles.

During the grinding of granite, clay ceramic, steel, and aluminum, [10] carried out TEM analysis of the abraded particles. Figure 5 shows the results. In Figure 5(a), a large number of particles $>1 \mu \mathrm{m}$ in diameter with compact nonspherical geometry are shown which were obtained during the grinding of granite. The micrograph of a large number of compact particles $>1 \mu \mathrm{m}$ with some abraded particles of clay ceramic $\ll 1 \mu \mathrm{m}$ is shown in Figure $5(\mathrm{~b})$. However, TEM images of the abraded particles of steel, as depicted by Figure 5(c), were characterized by open chain-like agglomerates of very fine primary particles indicating nucleation followed by growth through coagulation [10]. In the case of aluminum, again large compact and many nanometer sized particles were observed in the TEM image (Figure 5(d)). But from all the observations, [10] concluded that it was not possible to distinguish a source and generation mechanism by morphology alone. 
TABLE 1: Beyond the state of the art of particles' aerosol characterization techniques (source: Nanodevice).

\begin{tabular}{llcll}
\hline Device name & $\begin{array}{l}\text { Measured } \\
\text { physical metric }\end{array}$ & $\begin{array}{c}\text { Particles size } \\
\text { range }\end{array}$ & Operation principle & Level of development \\
\hline $\begin{array}{l}\text { DEKATI } \\
\begin{array}{l}\text { Low-cost total active } \\
\text { surface area monitor }\end{array}\end{array}$ & $\begin{array}{l}\text { Total active } \\
\text { surface area }\end{array}$ & $10 \mathrm{~nm}-3 \mu \mathrm{m}$ & $\begin{array}{l}\text { Aerosol particle charging in a unipolar } \\
\text { diffusion charger; electrical detection of } \\
\text { total amount of charged particles using } \\
\text { escaping charge technology. }\end{array}$ & $\begin{array}{l}\text { Operational } \\
\text { preprototype }\end{array}$ \\
\hline
\end{tabular}

Electrical mobility classified particle

charge concentration measured with two

TSI

NanoGuard

detectors with different response

characteristics. Signal thresholds trigger

method of operation (integral/size
Number concentration,

size distribution, $\quad<20-450 \mathrm{~nm}$

and morphology

finger print distribution scan/sampling with

electrostatic precipitator). Thermal

precipitator to continuously sample over 8-hour shift.

CNT particles in the air are preselected

using certain physical/chemical

Naneum

Real-time CNT

Number

concentration

All CNT

sources

Monitor

\section{Mass}

concentration

Naneum

Personal nanosampler

and size

distribution of

nanoparticles

Stockholm uni.

Sampler/preseparator

for aerosol fraction

deposited in the

anterior nasal region

Stockholm uni.

Sampler/preseparator

for aerosol fraction

deposited in the gas

exchange region

\begin{tabular}{|c|c|c|}
\hline $\begin{array}{l}\text { Grimm } \\
\text { NanoDevice }\end{array}$ & $\begin{array}{l}\text { Particle number } \\
\text { and size }\end{array}$ & $10 \mathrm{~nm}-27 \mu \mathrm{m}$ \\
\hline $\begin{array}{l}\text { DTU } \\
\text { MEMS-based } \\
\text { airborne } \\
\text { nanoparticles sensor }\end{array}$ & $\begin{array}{l}\text { Mass } \\
\text { concentration } \\
\text { and chemical } \\
\text { composition }\end{array}$ & $5-300 \mathrm{~nm}$ \\
\hline
\end{tabular}

\section{KIT}

Catalytic Activity

Aerosol Monitor

(CAAM)

$\begin{array}{lc}\text { Catalytic } & \text { Any with } \\ \text { activity } & \text { catalytic } \\ \text { concentration } & \text { activity }\end{array}$

Depending on

the metrics of

the used

monitor

Depending on

the metrics of

the used $\quad 20 \mathrm{~nm}-5 \mu \mathrm{m}$

monitor

$2 \mathrm{~nm}-5 \mu \mathrm{m}$

characteristics of CNT. Individual CNT

objects are then counted using optical

techniques.

Up to three cyclones collect larger

particles with a final cut-off of $300 \mathrm{~nm}$.

Particles with aerodynamic diameters

$<300 \mathrm{~nm}$ are collected on a series of

specially designed diffusion stages, with a variety of substrates.

Diffusive deposition with separation curves optimized with respect to the ICRP model and ISO/FDIS13138:2011.

Working prototypes; full characterization still underway

Near market

Near market

Aerodynamic and diffusive deposition with separation curves optimized with respect to the ICRP model and ISO/FDIS13138:2011.

Electrical and optical principles, currents, and single particle counting (light scattering).

Particle mass: gravimetry; chemical composition: closed information.

Early stage/still in the lab

Particles sampled for a short time on

(heated) filter.

Reaction gases added to start catalytic reaction.

Detection based on IR absorption of the product gas(es).

Reactant gas supply from lecture bottle(s) with flow control.

\begin{tabular}{lllll}
\hline $\begin{array}{l}\text { Fraunhofer IPA } \\
\text { CNT-detect }\end{array}$ & $\begin{array}{l}\text { Mass } \\
\text { concentration }\end{array}$ & $\begin{array}{l}\text { All CNT } \\
\text { sources }\end{array}$ & $\begin{array}{l}\text { Magnetic deposition followed by Raman } \\
\text { spectroscopy }\end{array}$ & Preprototype \\
\hline
\end{tabular}

Proof of

concept/preprototype
Preprototype

Preprototype

Preprototype

by abrasion using a brush. Clearly no visible free copper nanoparticles are observed showing that the nanoparticles are still embedded in the polymer matrix. But when the abrasion was done using a P1200 SiC paper, nanoparticles detached from polymer matrix (Figure 7(b)). In the similar fashion, when an epoxy-carbon nanotube nanocomposite was

Nanoparticles emitted from polycarbonate samples containing 3 wt $\%$ CNT by abrasion were analyzed by [11] through TEM. Figure 6 shows their observation. They observed the presence of nanometric polymer particles but no free CNTs. Figure 7 (a) shows the TEM picture of the nanoparticles emitted from polycarbonate samples (containing $10 \mathrm{wt} \% \mathrm{Cu}$ ) 


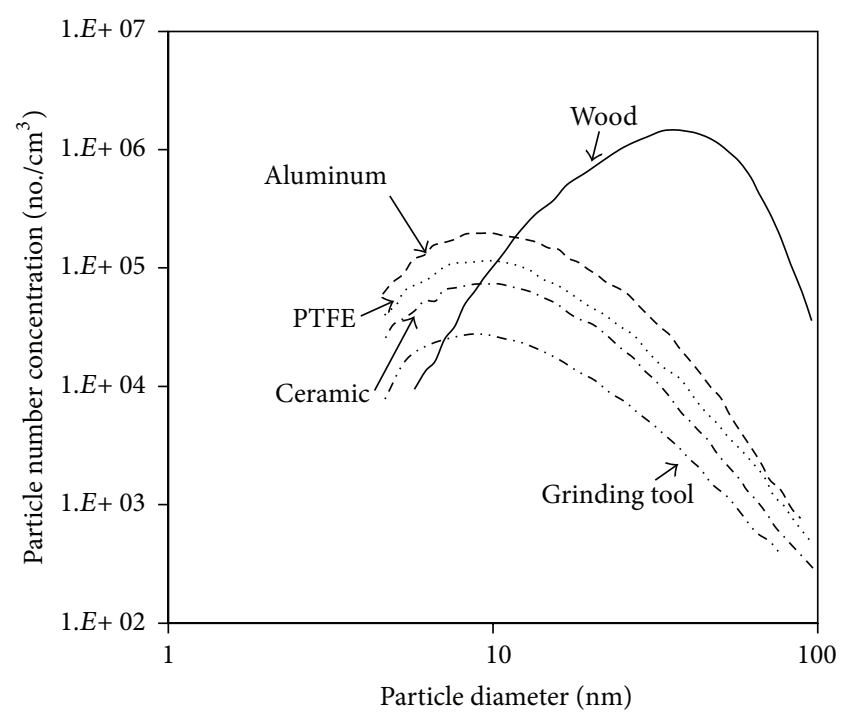

FIGURE 1: Composite of the ultrafine mode experimental results for the Dremel tool and various grinding substrates [10].

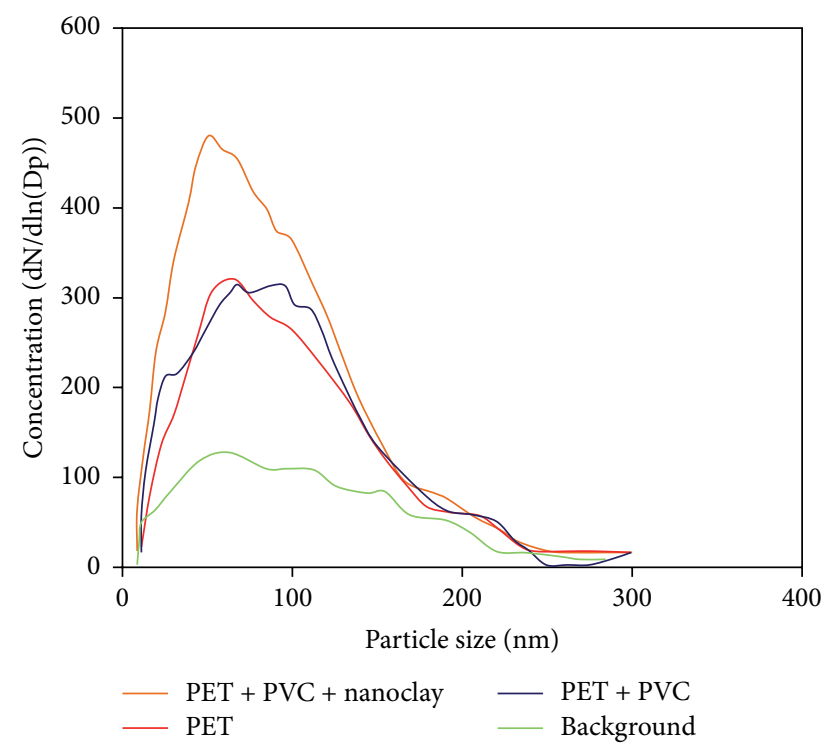

FIGURE 2: Effect of the addition of nanoclay to the PVC coated PET fabrics [11].

abrased using Taber [14], imaging by transmission electron microscopy (TEM) revealed that free-standing individual CNTs get emitted during abrasion. Figure 8 shows the results. Reference [15] carried out sanding of 8 different materials: polyamide (PA) with and without $\mathrm{SiO}_{2}$ nanoparticles, polyoxymethylene (POM) with and without carbon nanotubes (CNTs), hardened cement paste (CEM) with and without CNTs, and the same paste but with and without calcium silicate hydrate $(\mathrm{CSH})$.

Figure 9 shows the morphology of the emitted particles. They observed that the harder materials, that is, cement, irrespective of the presence of nanofillers, tend to generate significantly lower masses of powder, but in the form of smaller particles, in comparison to the softer materials, that

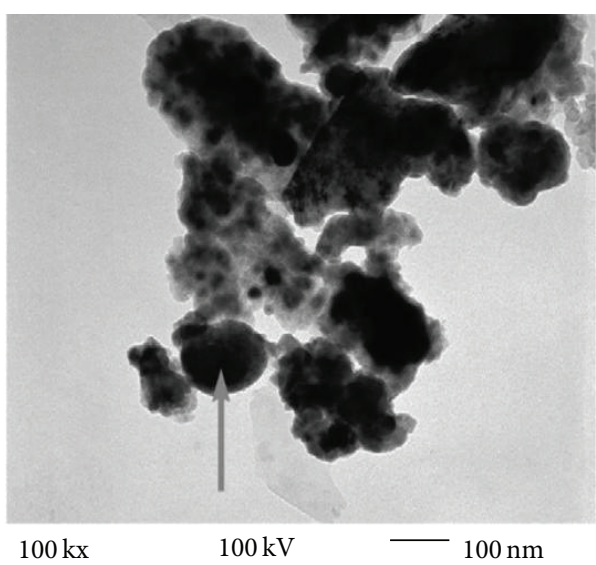

(a)

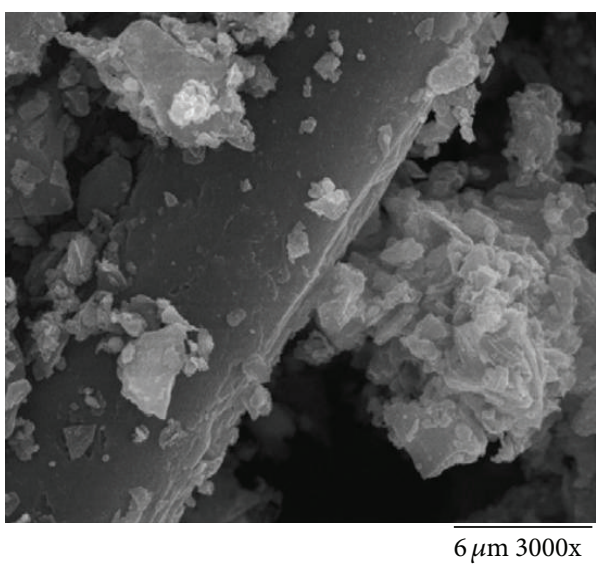

(b)

FIGURE 3: (a) TEM micrograph of wear debris [12]; (b) SEM image of fiber found in milled pad sample [12].

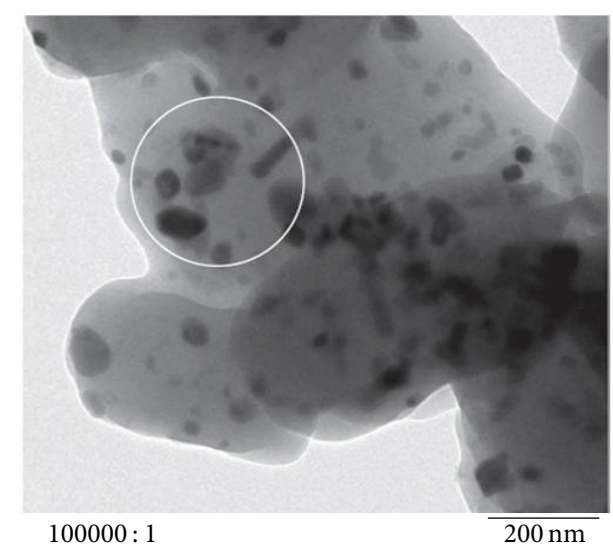

FIGURE 4: TEM image of wear from the steel panel with embedded zinc oxide particles [13].

is, thermoplastics. The size distribution was found to be dominated by a large fraction between typically 10 and $80 \mu \mathrm{m}$. For a detection threshold of $100 \mathrm{ppm}$, they were not able to detect any free nanofiller.

Reference [16] did the abrasion of filled and unfilled carbon fabric composites against an AISI-1045 steel pin using 


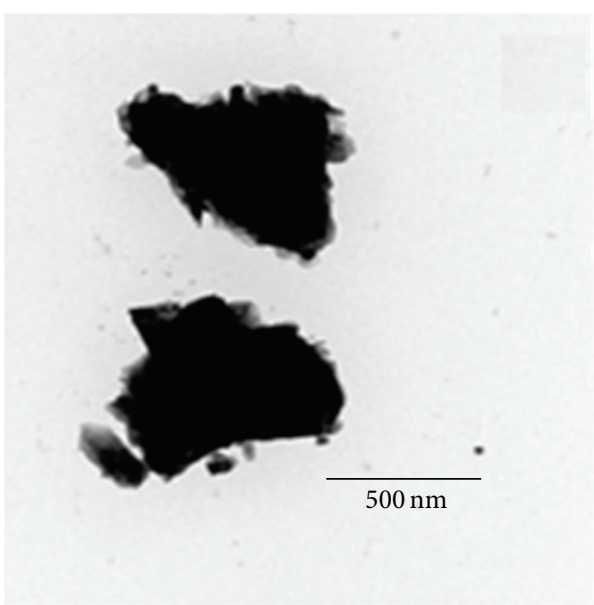

(a)

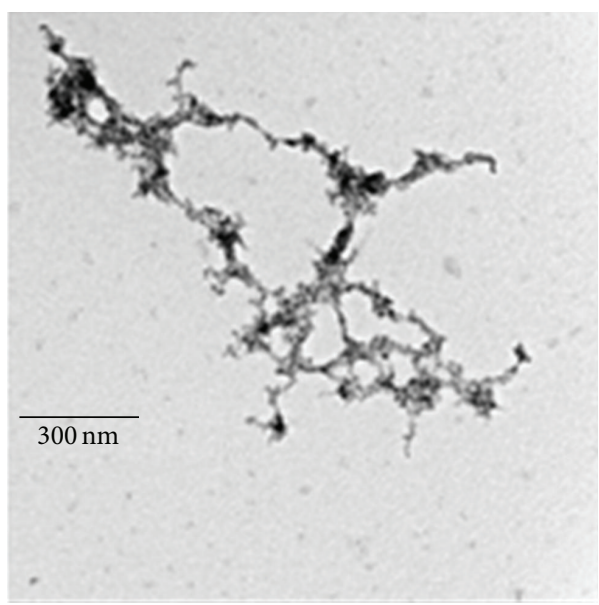

(c)

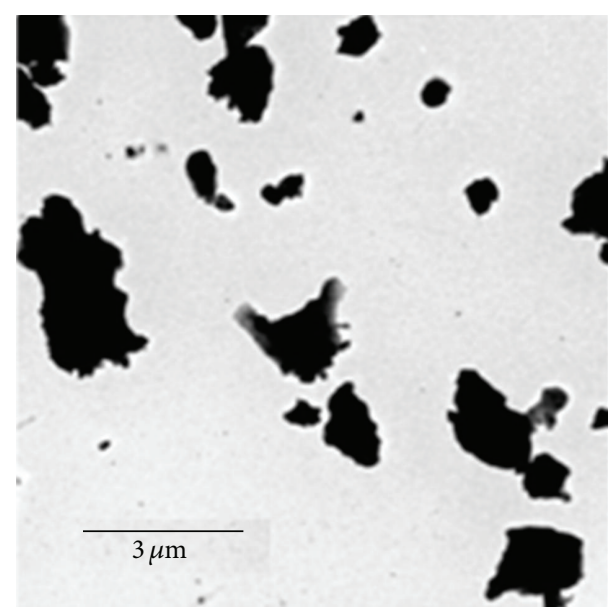

(b)

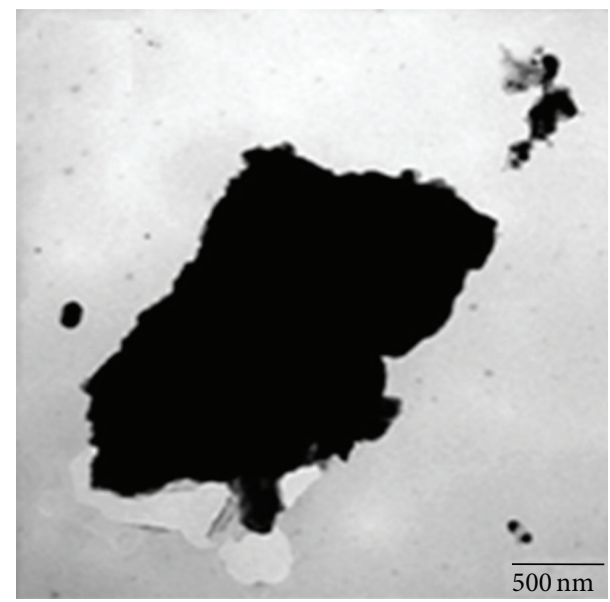

(d)

FIGURE 5: TEM micrographs of the various grinding substrates [10].

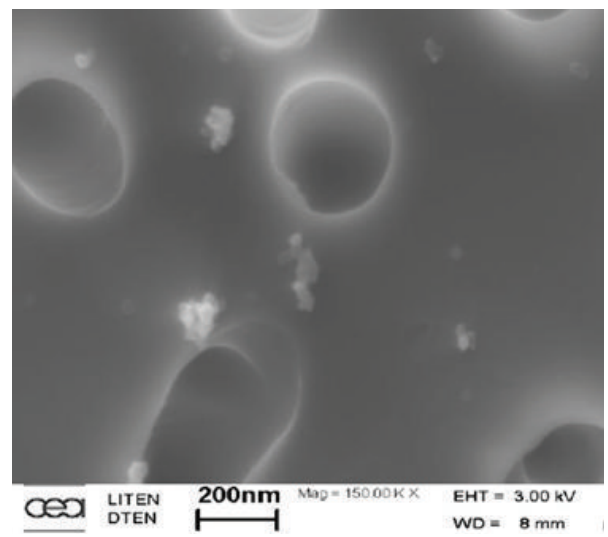

FIGURE 6: SEM observation of detected particles on filter out on the ELPI channel abraded using a steel brush [11].

a pin-on-disc arrangement. From Figure 10, showing SEM of the worn carbon fabric composites, it can be observed that most of the carbon fibers are pulled out from the fabric matrix on the worn surface of the unfilled carbon fabric composite (see Figure 10(a)), which indicates that the pure carbon fabric composite undertook a large contact stress and experienced severe peeling off as it slid against the steel at room temperature. Contrary to the above, the worn surface of the carbon fabric composite filled with 25\% Polyfluo Wax is smooth and the pulling-out and exposure of the carbon fibers are nearly invisible (see Figure 10(b)).

Moreover, the worn surface of the carbon fabric composite filled with $8 \%$ nano- $\mathrm{ZnO}$ or $5 \%$ nano-SiC is relatively smooth but still shows signs of carbon fiber pull-out (see Figures 10(c) and 10(d)), which agree well with the friction and wear behaviors of the composites filled with nano- $\mathrm{ZnO}$ and nano-SiC. Reference [17] recorded the abrasion behavior of the same steel under two different abrasion conditions: pinon-disc and paddle wear test. For consistency, they checked the behavior difference for 2 other grades of steel. Figures 11 and 12 show the difference between the surface characteristics obtained in two different wear conditions. As can be seen, the contact conditions active in the paddle wear test, that is, mainly impact abrasion and some sliding abrasion, generate heavily deformed surfaces with a relatively high amount of embedded fragments. In contrast, the contact conditions in 


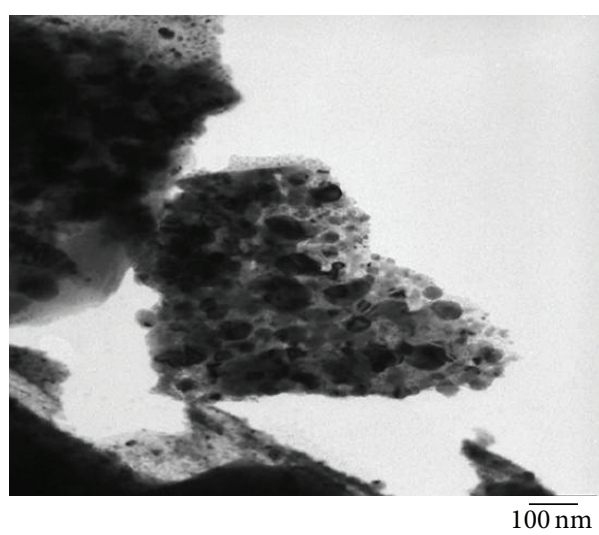

(a)

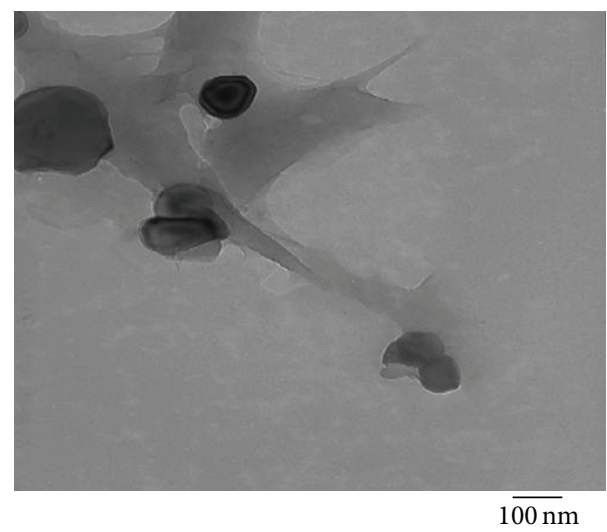

(b)

FIGURE 7: (a) TEM observation of detected particles abrased using a steel brush [11]; (b) TEM observation of detected particles abrased using a P1200 SiC paper [11].

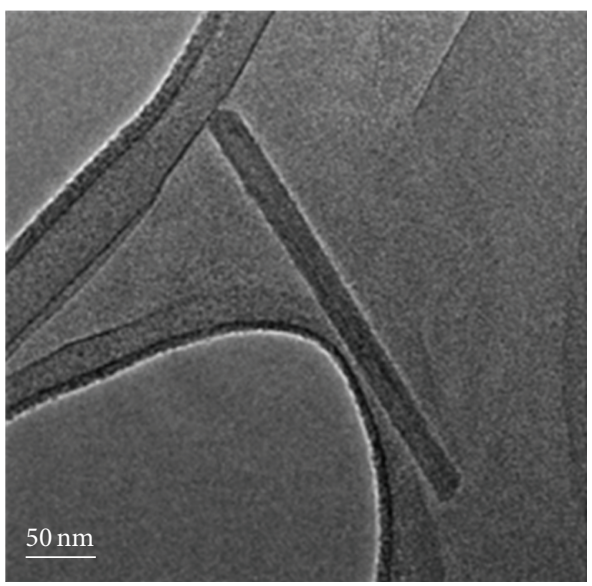

(a)

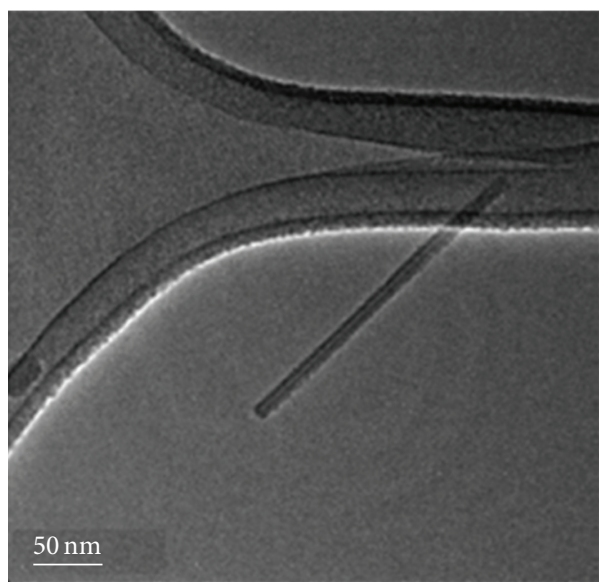

(b)

FIgURE 8: TEM images of free-standing individual CNTs [14].

the pin-on-disc test, that is, two-body abrasion, generate relatively well-defined worn surfaces without any embedded fragments. Characterization of the worn surfaces using 3D surface profilometry illuminates the pronounced difference in surface morphology, that is, the degree of surface plastic deformation, between specimens exposed to the two types of wear tests; see Figure 13.

Ultrahigh Resolution. This type of resolution is mainly required for analysis and control of the contact interactions between micro, or nanosized particles and nanomaterials surface topography. An understanding of these interactions is critical for any application that relies upon nanomaterials manipulation. AFM is used as a vital tool in understanding the fundamental mechanisms of particulate processes. Its use is further accompanied by a possible means to study the wear phenomena at atomic level. Reference [50] provides a greater insight into the influence of particle micro- and nanoroughness on adhesion by using AFM technique to determine an effective asperity radius of curvature for the contacting particle in the contact zone topography of glass and $\mathrm{UO}_{3}$ particles in contact with flat mica substrates. Reference [51] reviews briefly the measurements and interpretation of adhesion forces between microscopic probes and substrates having micro- and nanoscaled roughness characteristics. The study was concentrated on both rigid and deformable materials, with the probes larger than the size of roughness features of interacting surfaces. They concluded that controlling the deformation reduces and even eliminates the effects of nanoroughness on the probe-substrate contact area, promoting conditions described by the contact mechanics models (to be discussed in next section) for the spheresmooth substrate system. AFM finds another application in the exploration of the range of interaction forces [52] which can be utilized to predict, optimize, and design a variety of industrially relevant processes such as chemical mechanical polishing (CMP), powder flow and handling, and nanodispersions. Towards the resolution of the problem of 


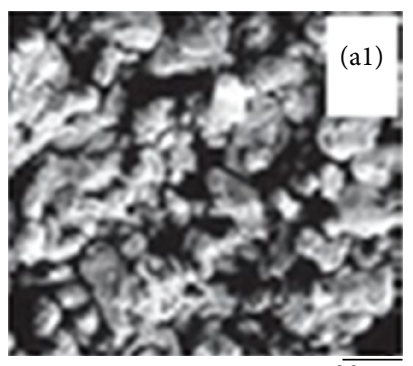

$\overline{20 \mu \mathrm{m}}$
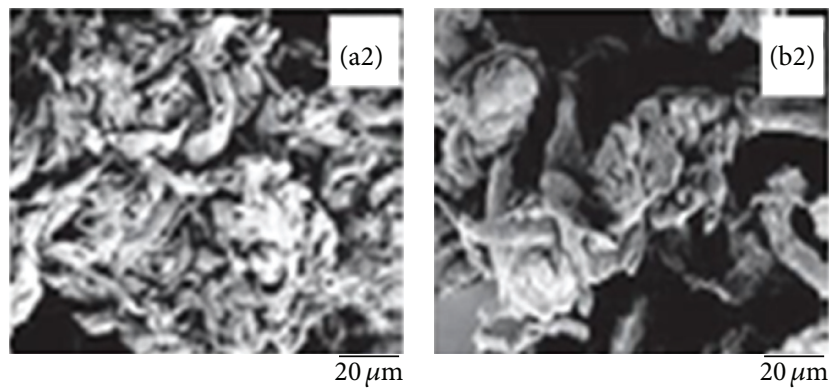

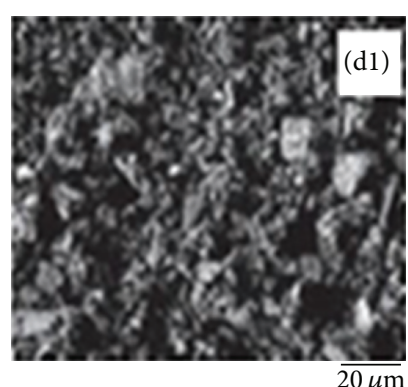

$20 \mu \mathrm{m}$
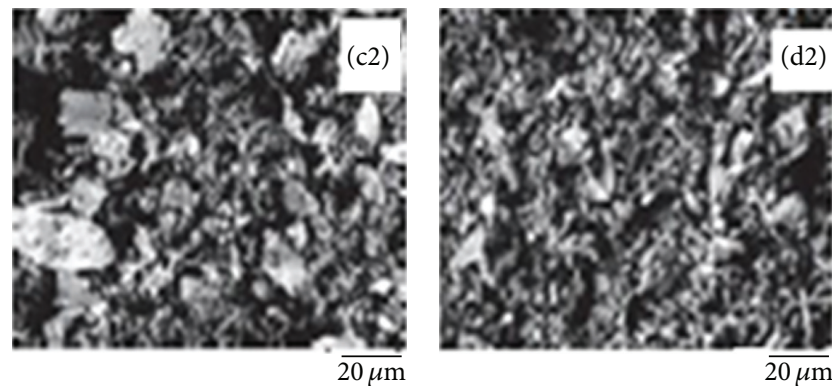

FIGURE 9: SEM images of powders generated by sanding nanocomposites and their reference materials [15]. (a) PA with (a1) and without (a2) $\mathrm{SiO}_{2}$, (b) POM with (b1) and without (b2) CNTs, (c) CEM with (c1) and without (c2) CNTs and (d) CEM with (d1) and without (d2) CSH.

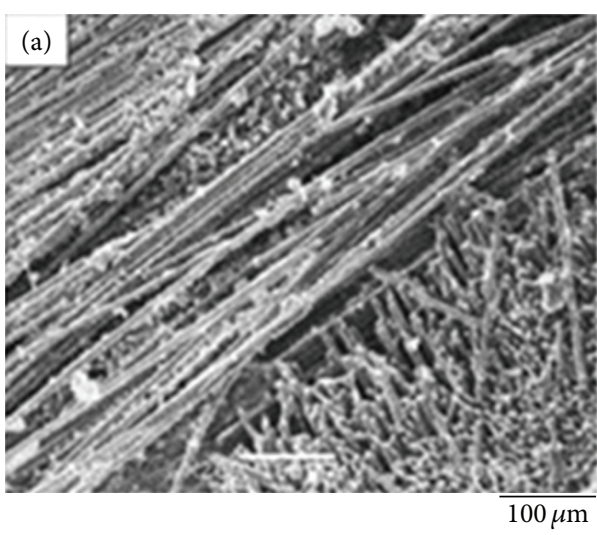

(a)

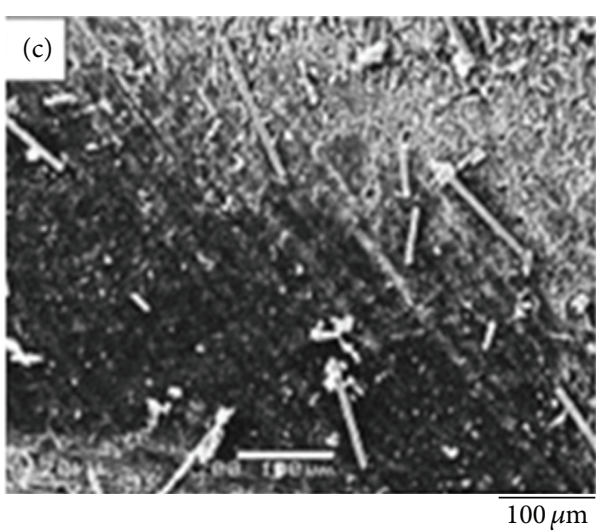

(c)

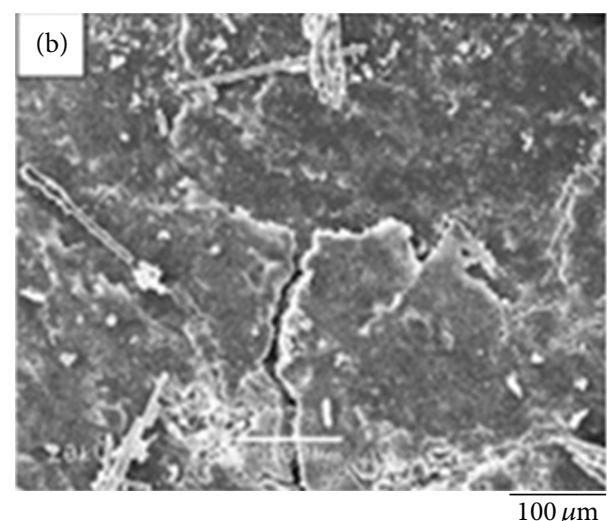

(b)

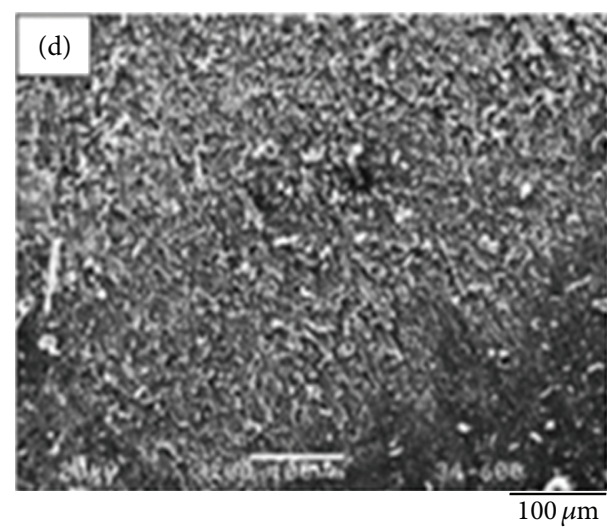

(d)

FIGURE 10: SEM morphologies of the worn surfaces of carbon fabric composites reinforced with different fillers at $274.4 \mathrm{~N}$ and room temperature: (a) pure CFC; (b) CFC + 25\% PFW; (c) CFC + 8\% nano-ZnO; (d) CFC + 5\% nano-SiC [16]. 

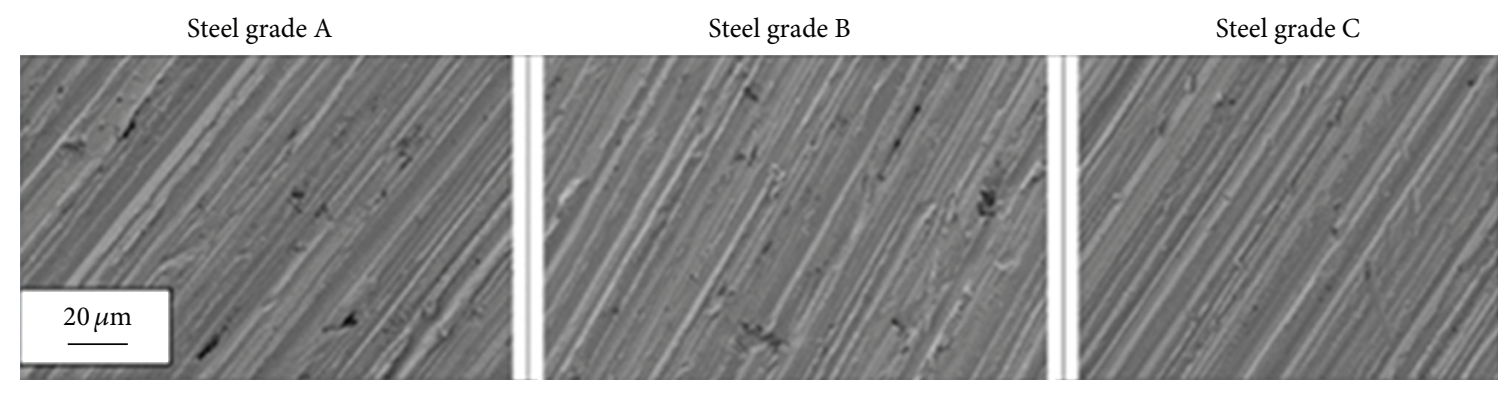

FIGURE 11: Surface characteristics of worn surfaces of the steel grades investigated when exposed to the pin-on-disc test as observed in the SEM [17].
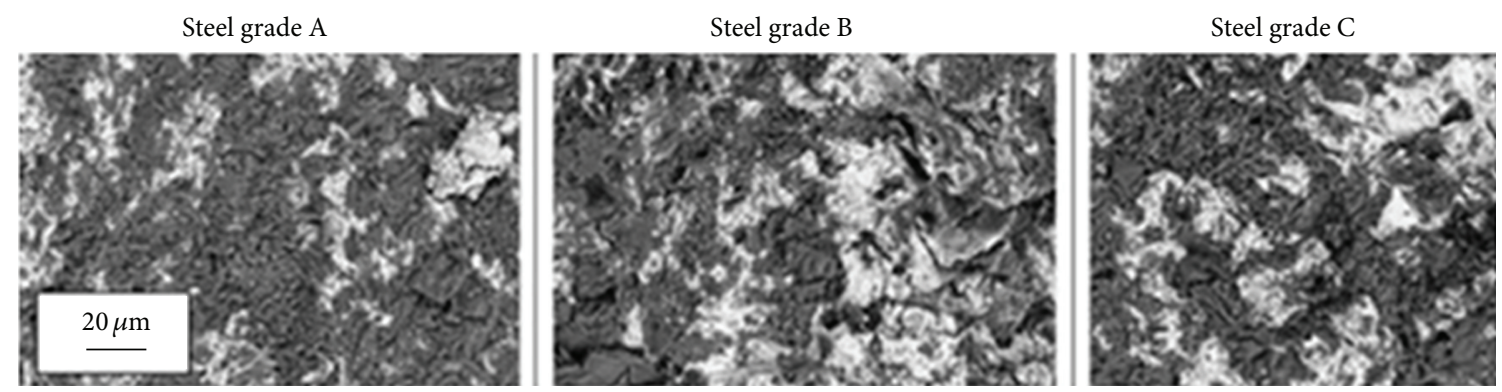

FIGURE 12: Surface characteristics of worn surfaces of the steel grades investigated when exposed to the paddle wear test as observed in the SEM [17].

powder flow by reducing the interparticle adhesion force, [53] indicated that their method of quantifying the interparticle adhesion force using AFM may be used to predict flow behavior of original (cohesive) and surface modified (previously cohesive) powders utilizing very small samples and that the surface modification can drastically improve the powder flow for industrially relevant materials. A similar intergranular adhesion study was carried out by [54] which reviews progress in micro/nanoparticle manipulation and particle-substrate adhesion studies. It found AFM to be the most commonly used tool for particle manipulation studies.

A new approach using AFM was proposed by [55] to carry out 3D numerical surface characterization of wear debris generated from artificial joints. The method developed from the study was found to be feasible to quantify the surface characterization of nano- and micro-sized wear particles. Emphasizing on the dependency of the wear particles aerosol generation on the material properties like viscoelastic and fracture properties of one of the widely used polymeric materials, epoxy resin, [56] concluded that such material properties can be tailored by changing the network or crosslink structure by blending monomers with different molecular weights which were characterized using AFM. On a similar type of substrate, [57] performed some nanoscratch tests and studied surface morphology using AFM tip. Reference [58] used AFM tips to simulate a sharp single asperity travelling over a stainless steel surface and demonstrated that nanowear experiments, at controlled contact pressures and scanning speeds, can be performed in almost any type of material. The same AFM enabled them to observe and characterize the nano/micro worn regions with a high lateral resolution.
Although AFM can image surfaces with a nanometer spatial resolution, the finite size of standard tips means that pores, pits, or grooves with dimensions similar to or smaller than the tip apex will not be accurately imaged. Furthermore, standard tips are made of silicon or silicon nitride which are prone to wear when subjected to stress. In this effect, [59] performed tests to compare the imaging performance of ultrasharp Si AFM tips, CNT AFM tips prepared by a Langmuir-Blodgett (LB) technique, and CNT AFM tips prepared by a chemical vapor deposition (CVD) technique. In general, ultrasharp Si tips allowed for a remarkably good resolution of the height variations in niobium film with a nanoscale polycrystalline structure. Their height resolution was found to be excellent although their lateral resolution was not as good as the one of CNT AFM tips.

\section{Theoretical Modeling}

Modeling of wear processes allows identifying the most important factors influencing wear and hence aerosol generation. Due to this reason, more than a century has been spent for searching such models which are both general and based on fundamental aspects. However, this search is still elusive. Reference [60] established the first wear model in which the wear volume rate is shown to be proportional to the normal load. Holm considered the plastic deformation as the predominant mechanism for the material removal. In the classical abrasive wear model proposed by Archard, the wear volume is predicted to be a function of sliding distance, the applied normal load, and the material hardness. In 1962, [61] presented a simple model for the abrasion of steel sliding 


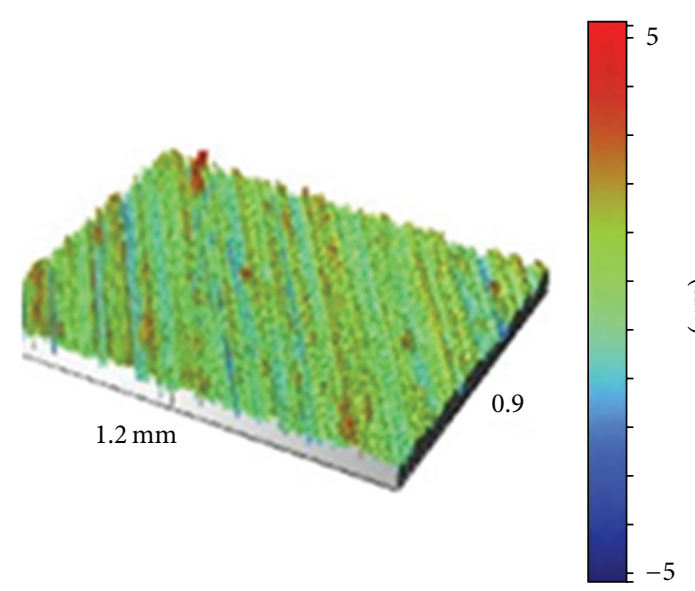

(a)

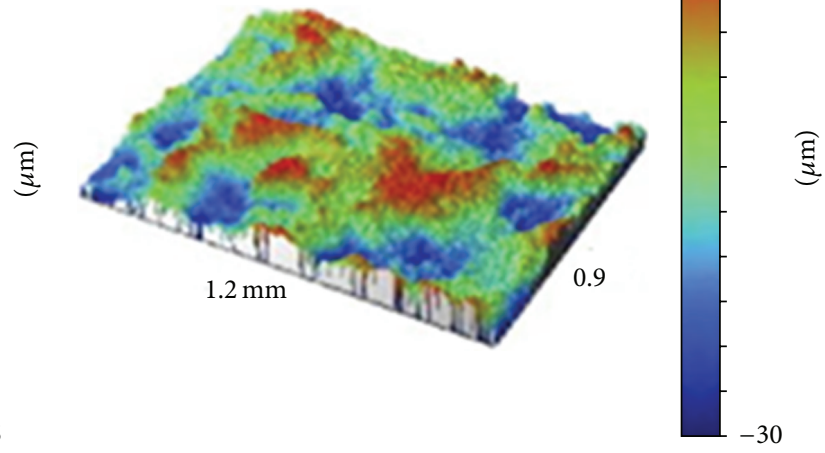

(b)

FiguRE 13: 3D surface profiles of worn specimens of steel grade A exposed to the pin-on-disc test (a) and the paddle wear test (b) [17].

against silicon carbide paper. The model takes into account the shape of the contacting abrasive particles, their attitude in the abrasive paper, and their deterioration with use. Other more detailed models have also been developed to predict the abrasive rates of materials under specific conditions. Reference [62] stated hardness to be the most important property that determines the wear rate. This model is simple and provides a qualitative theoretical basis. But later extensive studies have shown that the other properties can significantly affect the abrasive wear and the predicted wear coefficient is at least an order of magnitude larger than experimentally observed values. Reference [63] proposed a model for wear of brittle solids under fixed abrasive conditions. Reference [64] presented a model for two-body abrasive wear based on localization of plastic deformation. This model assumes that the localization of deformation in the near-surface regions underneath the abrasive grains is responsible for the wear generation. From this onwards, it started being understood that the correct wear behavior can be identified by inculcating the factors accounting for plasticity and governing yield criteria. Reference [20] has used the theoretical analysis of the steady state of two sliding asperities to investigate the mechanics involved in the sliding contact of two rough surfaces (one hard and one soft). Their analysis was restricted to the case when the roughness on the harder surface is regular, that is, all asperities have the same height and curvature, and it is only the soft surface that is randomly rough, that is, asperities with a Gaussian height distribution and constant curvature.

Some models [65] also incorporate various thermophysical and slip line field analysis methods. Most of the existing models, however, mainly deal with single particle contact conditions. Reference [66] tried to justify the wear by studying the frictional force evolution with the combined sliding between two bodies. He explained the transition between the micro and macro/gross displacement/slip experimentally and showed that it can proceed in a number of ways. The total frictional force, $F=F_{\text {spring }}+F_{\text {slip }} . F_{\text {spring }}$, is the frictional load from the active asperities which have not reached their limiting elastic limit and $F_{\text {slip }}$ is the contribution from asperities which have reached their elastic limit:

$$
F=\frac{8}{15} \mu C A_{0} E^{*} R^{1 / 2}\left[\lambda^{5 / 2}-\left(\lambda_{n}-\frac{4 G^{*} \delta}{\mu E^{*}}\right)^{5 / 2}\right],
$$

where $\mu$ is the coefficient of friction, $C$ is the constant relating the number of contacts per unit area and the approach of the surfaces, $A_{0}$ is the apparent area of contact, $E^{*}$ is the composite modulus of elasticity of two bodies having their respective elastic moduli as $E_{1}$ and $E_{2}$ :

$$
\frac{1}{E^{*}}=\frac{1-v_{1}^{2}}{E_{1}}+\frac{1-v_{2}^{2}}{E_{2}}
$$

$R$ is the spherical asperity radius, $\lambda_{n}$ is the normal approach, $\delta$ is the tangential displacement of the asperity, and $G^{*}$ is the composite shear modulus of two bodies having their respective moduli as $G_{1}$ and $G_{2}$ :

$$
\frac{1}{G^{*}}=\frac{2-v_{1}}{G_{1}}+\frac{2-v_{2}}{G_{2}} .
$$

Reference [67] presented a general wear model for wear rate and specific wear energy of materials in two-body abrasive wear (one hard and one soft) under multiple contact conditions by considering wear mode transitions and material removal fraction. Using the proposed model, the authors showed typical variations of wear rate as a function of grit size of the abraser, thereby explaining the grit size effect:

$$
K=\frac{V}{P S}=\frac{N A_{a}}{P} \int_{h_{m}}^{h_{z}} f(z) A_{i} \beta d z,
$$

where $N$ is the number of abrasive particles on unit area of the hard material, $A_{a}$ is the apparent area of contact, $P$ is the apparent contact pressure, $h_{z}$ is the maximum height of an asperity, $h_{m}$ is the mean height, $f(z)$ is the asperity height distribution, $A_{i}$ is the cross section area of a groove 
produced in the soft material by abrasion of an individual abrasive particle, and $\beta$ is the fraction of material removed from the groove produced. For the first time, [68] introduced numerical methods, in particular, Monte Carlo, to model a two-body abrasion process. The model is also compared with experimental values and the results were found to be in agreement with each other. In the model, the grit was considered to be in conical shape with the geometry parameters - height, radius of the tip, position distribution, and conical angle-as the input variables. Reference [69] provided an energy description of the wear mechanisms in hard $\mathrm{TiN}$ and $\mathrm{TiC}$ coatings during oscillating sliding contacts. Reference [70] pointed out that the abrasive wear rates of materials may be very simply related to their mechanical properties, provided wear takes place under very simple conditions. However, wear rates in many practical situations can be controlled by effects which either relate to mechanical properties in more subtle ways or which are controlled by quite different parameters. Mechanics models of the abrasive process provide a means of linking these different effects together to understand better the effects, which may determine wear under particular conditions. They can also help to design tests to measure the properties of a material under conditions similar to those pertaining in abrasion. With the argument that the abrasion process varies substantially from one material pair to another during a single test, [71] put forward a wear law for Boron Carbide $\left(\mathrm{B}_{4} \mathrm{C}\right)$ coatings when slid against AISI 52100 steel. The wear law suggests that the total abrasion rate is the function of the volume of the steel removed and total sliding distance. Abrasion experiments were carried out under various contact conditions, dry or wet, and corresponding values of the variables were calculated for every condition. Recently [72] understood the value of theoretical modeling of wear for designing and optimizing tribological systems, particularly during unlubricated conditions. They presented a generic, asperity level, theoretical model for predicting wear evolution in a plain contact. They have justified the material removal by saying that, when the energy accumulation in an asperity, owing to repeated elastic-plastic deformation, exceeds a certain threshold, the asperity breaks off. The simulation results show, both for unidirectional and bidirectional sliding, a qualitative agreement with experimental observations. Apart from the running-in process, a linear trend was observed between the wear volume and the energy dissipation in the contact. References [73, 74] modeled fretting behavior of nominally flat rough surfaces. Individual asperity-scale contact forces have been formulated and added statistically to each other to obtain the fretting response of a flat rough contact.

\section{Conclusion and Discussions}

In the present paper, different aspects towards the study of the wear particles have been presented after a thorough investigation and review of the contemporary studies. The primary focus of this paper is to develop a state of art of the interdisciplinary studies conceived towards the aerosolization of wear particles. It has been found that there has been no significant progress towards the measure of the wear particles aerosols. Despite a widespread use of various wear test methods and various steps of the nanoproduct's life cycle assessment, the measure of in-process generation of wear particles aerosols is still an interdisciplinary challenge, and finds only impact on few norms. The fundamental studies which were conceived in this direction have dealt with this aspect experimentally with a limited scope. There has already been a wide scale development of the instrumentation for particles aerosols characterization. However, it mainly suffers from its semiquantitative approach (due to the exclusion of the stray particles generated during wear process) and inability of the separation of the particles under study from background noise on an industrial scale. Hence, various reliable, robust, novel, portable, and easy-to-use instruments for characterizing wear particles are required for the next generation technology which is able to couple particle release characterization to wear scenarios in a standardized way.

Apart from the experimental scenario, the theoretical understanding of various underlying physical phenomena and identification of their key parameters giving rise to the aerosolization of the wear particles need much attention. Both theoretical and experimental approaches are complementary to each other to foresee beyond the state of the art so as to identify and understand the in-process occurring physical phenomena.

From the present study we can infer that in spite of various limitations, the past studies provide sufficient background and platform to continue the intended study in the direction suggested. It is on the basis of the investigation of these studies only that one can enlist some of the possible major factors affecting the quantity, morphology, size, nature, and mechanism of generation of the wear particles aerosols.

(1) Surface Conditions. These conditions mainly include the roughness and porosity of the surface. However, if there is any physical treatment like application of a coating through pulverization, chemical treatment like etching, and mechanical treatment like machining, generation of wear particles aerosols can be equally affected. The properties like isotropicity, anisotropicity, and photogenicity of a surface also play an important role in this aspect.

(2) Stress Conditions. The value of the load acting on the surface and its nature, that is, static or dynamic, is also important towards the particles aerosols generation as it is the deciding factor for the occurrence of an elastic or plastic or elastoplastic deformation of the surface during abrasion which later gives rise to fracture nucleation.

(3) Temperature Dissipation. The temperature dissipation is very decisive in the ductile surfaces like metals. It is the dissipation or accumulation of the heat that results in the progressive adhesion of the wear particles which may or may not inhibit the further wear. Also it renders an indecisive deterioration of the surface.

(4) Contact Condition. This factor cannot be considered as totally independent from other conditions but it would be 
much simpler to consider it separately while formulating the wear particles aerosol. These conditions include the interference of the two mating surfaces produced when brought in contact. With specific surface and stress conditions, there may be a development of stress concentration which can enhance the aerosol generation. The adhesion of the surfaces to each other also depends on the contact conditions.

(5) Nature of the Material. The material properties like hardness, brittleness, ductility, and so forth seem to affect the aerosol generation. Incrystalline solid, molecular structure and forces contribute towards the inbuilt surface forces or tension which further decides the stability of surface.

In order to foresee beyond the state of the art, the eradication of some common limitations in all the studies done to this date is required. One of the major problems in the wear models presented up to date has been the lack of the representation of real surface geometric complexities due to the mathematical, physical, and experimental intricacies. It needs to be eliminated and should be supported by numerical methods in order to be more reliable and efficient. Also, the future works should inculcate various phenomenological, micromechanical, and microscale interactions between the mating surfaces. Ultrahigh resolution microscopy finds its use here. The wear tests should be coupled to real life industrial case studies which could contribute to future standardization activities. A new generation of sampling methods for use in industry could aid such a coupling.

With this, one should also not forget that the science behind the wear generation in the engineering materials is always evolving with the evolution of the materials with time. In the present study, it has been found that an important milestone in the studies of the wear generation, owing to surface microscopic studies, has been the transition of the studies from the macroscopic interactions to microscopic interactions of the surfaces. Therefore, there arises a need to have another milestone of the transition from microscopic to nanoscopic interactions. This will allow having a sufficient theoretical basis to study the nanometric wear particles aerosols. This transition becomes more pertinent with present overwhelming use of manufactured nanomaterials (MNM) in the commercial products due to which more and more humans are susceptible towards the exposure of the nanoparticles aerosol which may pose big health problems.

Therefore, such an approach may prove to be a major contribution in the sustainable and durable development of the technology so as to have nanosafety by design rules for nanoproducts.

\section{Annexure}

This section describes the solicitation methods used in the studies mentioned in the paper along with the references where they are employed.

5.1. Taber Abrasion Tester. As employed by [13, 30, 31], Taber abraser is a well-known abrading method. Its use is widespread and is described in many national and international standards (e.g., DIN 53754:1977, DIN 68861-2:1981,
ISO 5470-1:1999, ASTM C 1353-07, and ASTM D 406095: 2007). In this system, a horizontal arm is incorporated that reciprocates in a linear motion. Attached to the end of the arm is a precision bearing spline shaft that creates a "free-floating" test system and permits vertical movement. The test attachments are affixed to the bottom of the spline shaft and a weight support is mounted to the top. As the horizontal arm strokes back and forth, the test system rises or lowers vertically as the test attachment follows the contours of the specimen. Reference [27] generated sanding dust using a commercial hand-held orbital sander with an internal fan for dust removal. A sand paper with fine grit size was employed to enhance the chances of fine particles generation.

5.2. Ball Milling. The process of ball milling is a type of grinding in which a cylindrical device is used in grinding or mixing materials. Ball mills rotate around a horizontal axis, partially filled with the material to be ground plus the grinding medium. Different materials are used as media, including ceramic balls, flint pebbles, and stainless steel balls. An internal cascading effect reduces the material to a fine powder with particle size range in submicrons. Reference [12] ball milled semimetallic polymer matrix composite brake linings using a laboratory vibrating ball mill VM4 with tungsten carbide beads. The brake pads were removed from the backing plates, cut into segments of approximately $1 \mathrm{~cm}^{3}$, and repeatedly ball milled for $10 \mathrm{~min}$ and sieved through a $200 \mu \mathrm{m}$ sieve until sample particles with major fractions below $200 \mu \mathrm{m}$ were obtained.

5.3. Dynamometer. Reference [12] used a full scale brake dynamometer in an environmental chamber with wind tunnel simulating airflow. The dynamometer was fed with two semimetallic polymer matrix composite brake linings, each weighing $113 \mathrm{~g}$, in eight tests. Each lining set was run twice consecutively, the first run using a resurfaced brake rotor and the second using the same rotor from the first run without any changes. Wear debris collected from the dynamometer was sieved using USA Standard Testing Sieve.

\subsection{Ultraviolet Photodegradation and Chemical Treatment.}

These methods of wear treatment, through degradation, are applicable for the polymeric compounds or the organic coatings in order to evaluate their durability as well as mechanical and thermal properties. Knowledge of aging behavior and mechanism of these materials is of great help for antiaging research. References $[75,76]$ studied the photodegradation mechanism and after products of polypropylene (PP) nanocomposites. Similarly, [77] also studied these nanocomposites, namely, $\mathrm{PP} / \mathrm{CaCO}_{3}$ and $\mathrm{PP} / \mathrm{SiO}_{2}$, outdoor for 88 days against unfilled PP. They found that the PP nanocomposites are more susceptible to photodegradation than the unfilled ones and, therefore, have higher tendency for wear. Also, the oxidation rate increases with the filler amount.

Chemical treatment on the surface layer is mainly done by the commercial mirror manufacturers. The layer is composed of the layers or films of copper or silver. Within standard testing methods, the copper chloride modified acetic acid 
salt spray test is employed (CASS test, NF ISO 9227 12/1991). During this test, the surface layer on the mirrors shows macroscopic degradation of the metallic layers from the edges and more randomly at the centre of the samples. Reference [78] adopted this methodology and carried out infrared spectroscopy for their study.

5.5. Emission Chamber. Although this technique is not directly responsible for the wear generation, hence the aerosol generation, but it acts as an interconnection between the aerosols generation mechanism and their measurement mechanism. It is a sampling hood which almost completely encapsulates the sample suction zone behind the aerosol particles generation site. With the help of the emission chamber, particle loss in the air flow of the laminar low box can be avoided. This technique has been widely adopted by $[10,11,13,27,48]$ for ensuring very low or zero background particles presence.

5.6. Grinders and Sanders. Grinding and sanding are most common operations in the workshops. In order to assess the safety associated with these processes, there have been many attempts. Reference [47] did an investigation on the production of dust by hand sanders. Reference [10] worked on the aerosols generated by using a Multipro Dremel Grinder, model 395, with a variable speed tool having rotational speed from 5000 to $30000 \mathrm{rpm}$. A cylindrical grinding wheel, composed of sintered aluminum oxide, was used for the experiments. Reference [27] performed sanding of nanoparticles containing paints using a commercial handheld orbital sander (Metabo Model FSR 200 Intec) with an internal fan for dust removal. Grit size 240 sanding paper was used for sanding.

\section{Conflict of Interests}

The authors declare that there is no conflict of interests regarding the publication of this paper.

\section{Acknowledgement}

The authors would like to thank the French Ministry of Environment (DRC 33 and program 190), ANSES (Nano-data project, CRD NanoEmis) and SERENADE for financing the work. The equal gratitude goes to C. Bressot and O. AguerreChariol at INERIS for their support during the study.

\section{References}

[1] P. Kulkarni, P. A. Baron, and K. Willeke, Aerosol Measurement: Principle, Techniques and Applications, John Wiley and Sons, Hoboken, NJ, USA, 3rd edition, 2011.

[2] G. Oberdörster, E. Oberdörster, and J. Oberdörster, "Nanotoxicology: an emerging discipline evolving from studies of ultrafine particles," Environmental Health Perspectives, vol. 113, pp. 823-839, 2005.

[3] P. Houdy, M. Lahmani, and F. Marano, Nanoethics and Nanotoxicology, Springer, Heidelberg, Germany, 1st edition, 2011.
[4] C. Bekker, D. H. Brouwer, E. Tielemans, and A. Pronk, "Industrial production and professional application of manufactured nanomaterials-enabled end products in Dutch industries, potential for exposure," The Annals of Occupational Hygiene, vol. 57, no. 3, pp. 314-327, 2012.

[5] S. Kaluza, J. K. Balderhaar, B. Orthen et al., "Workplace exposure to nanoparticles," 2010.

[6] C. Buzea, I. I. P. Blandino, and K. Robbie, "Nanomaterials and nanoparticles: sources and toxicity," Biointerphases, vol. 2, no. 4, pp. MR17-MR172, 2007.

[7] Scientific Committee on Emerging and Newly Identified Health Risks (SCENIHR), "The appropriateness of existing methodologies to assess the potential risks associated with engineered and adventitious products of nanotechnologies," Health and Consumer Protection Directorate-General, European Commission, 2006.

[8] C. Ostiguy, B. Roberge, L. Ménard, and C. A. Endo, "Best Practices Guide to Synthetic Nanoparticle Risk Management, L'Institut de recherche Robert-Sauvé en santé et en sécurité du travail (IRSST)," Report R-599, 2009.

[9] National Institute for Occupational Safety and Health (NIOSH), "Centers for Disease Control and Prevention (CDC), Approaches to Safe Nanotechnology," Publication 2009-125, 2009.

[10] A. T. Zimmer and A. D. Maynard, "Investigation of the aerosols produced by a high-speed, hand-held grinder using various substrates," Annals of Occupational Hygiene, vol. 46, no. 8, pp. 663-672, 2002.

[11] A. Guiot, L. Golanski, and F. Tardif, "Measurement of nanoparticle removal by abrasion," Journal of Physics, vol. 170, Article ID 012014, 2009.

[12] J. Kukutschová, V. Roubíček, K. Malachová et al., "Wear mechanism in automotive brake materials, wear debris and its potential environmental impact," Wear, vol. 267, no. 5-8, pp. 807-817, 2009.

[13] M. Vorbau, L. Hillemann, and M. Stintz, "Method for the characterization of the abrasion induced nanoparticle release into air from surface coatings," Journal of Aerosol Science, vol. 40, no. 3, pp. 209-217, 2009.

[14] L. Schlagenhauf, B. T. T. Chu, J. Buha, F. Nüesch, and J. Wang, "Release of carbon nanotubes from an epoxy-based nanocomposite during an Abrasion process," Environmental Science and Technology, vol. 46, pp. 7366-7372, 2012.

[15] W. Wohlleben, S. Brill, M. W. Meier et al., "On the lifecycle of nanocomposites: comparing released fragments and their in-vivo hazards from three release mechanisms and four nanocomposites," Small, vol. 7, no. 16, pp. 2384-2395, 2011.

[16] Z.-Z. Zhang, F.-H. Su, K. Wang, W. Jiang, X.-H. Men, and W.M. Liu, "Study on the friction and wear properties of carbon fabric composites reinforced with micro- and nano-particles," Materials Science and Engineering A, vol. 404, no. 1-2, pp. 251258, 2005.

[17] J. Rendón and M. Olsson, "Abrasive wear resistance of some commercial abrasion resistant steels evaluated by laboratory test methods," Wear, vol. 267, no. 11, pp. 2055-2061, 2009.

[18] F. P. Bowden and D. Tabor, The Friction and Lubrication of Solids, Clarendon Press, Oxford, UK, 1954.

[19] A. P. Green, "Friction between unlubricated metals: a theoretical analysis of the junction model," Proceedings of the Royal Society A, vol. 228, pp. 191-204, 1955.

[20] A. Kapoor, J. A. Williams, and K. L. Johnson, "The steady state sliding of rough surfaces," Wear, vol. 175, no. 1-2, pp. 81-92, 1994. 
[21] U. Olofsson and L. Hagman, "Model for micro-slip between flat surfaces based on deformation of ellipsoidal elastic bodies," Tribology International, vol. 30, no. 8, pp. 599-603, 1997.

[22] P. J. Blau, Friction, Lubrication, and Wear Technology Vol. 18, ASM Handbook, 1992.

[23] O. Le Bihan, N. Shandilya, L. Gheerardyn, O. Guillon, E. Dore, and M. Morgeneyer, "Investigation of the release of particles from a nanocoated producted," Advances in Nanoparticles, vol. 2, pp. 39-44, 2013.

[24] K. Hokkirigawa and K. Kato, "An experimental and theoretical investigation of ploughing, cutting and wedge formation during abrasive wear," Tribology International, vol. 21, no. 1, pp. 51-57, 1988.

[25] M. A. McCawley, M. S. Kent, and M. T. Berakis, "Ultrafine beryllium number concentration as a possible metric for chronic beryllium disease risk," Applied Occupational and Environmental Hygiene, vol. 16, no. 5, pp. 631-638, 2001.

[26] K. T. Choe, M. Trunov, S. A. Grinshpun et al., "Particle settling after lead-based paint abatement work and clearance waiting period," The American Industrial Hygiene Association Journal, vol. 61, no. 6, pp. 798-807, 2000.

[27] I. K. Koponen, K. A. Jensen, and T. Schneider, "Sanding dust from nanoparticle-containing paints: physical characterisation," Journal of Physics, vol. 151, Article ID 012048, 2009.

[28] B. D. Garg, S. H. Cadle, P. A. Mulawa, P. J. Groblicki, C. Laroo, and G. A. Parr, "Brake wear particulate matter emissions," Environmental Science and Technology, vol. 34, no. 21, pp. 44634469, 2000.

[29] P. G. Sanders, N. Xu, T. M. Dalka, and M. M. Maricq, "Airborne brake wear debris: size distributions, composition, and a comparison of dynamometer and vehicle tests," Environmental Science and Technology, vol. 37, no. 18, pp. 4060-4069, 2003.

[30] H.-J. Gläsel, F. Bauer, H. Ernst et al., "Preparation of scratch and abrasion resistant polymeric nanocomposites by monomer grafting onto nanoparticles," Macromolecular Chemistry and Physics, vol. 201, no. 18, pp. 2765-2770, 2000.

[31] O. Knotek, E. Lugscheider, F. Löffler, G. Krämer, and H. Zimmermann, "Abrasive wear resistance and cutting performance of complex PVD coatings," Surface and Coatings Technology, vol. 68-69, pp. 489-493, 1994.

[32] L. Reijnders, "The release of $\mathrm{TiO}_{2}$ and $\mathrm{SiO}_{2}$ nanoparticles from nanocomposites," Polymer Degradation and Stability, vol. 94, no. 5, pp. 873-876, 2009.

[33] J. K. Pandey, K. Raghunatha Reddy, A. Pratheep Kumar, and R. P. Singh, "An overview on the degradability of polymer nanocomposites," Polymer Degradation and Stability, vol. 88, no. 2, pp. 234-250, 2005.

[34] X. D. Chen, Z. Wang, Z. F. Liao, Y. L. Mai, and M. Q. Zhang, "Roles of anatase and rutile $\mathrm{TiO}_{2}$ nanoparticles in photooxidation of polyurethane," Polymer Testing, vol. 26, no. 2, pp. 202-208, 2007.

[35] R. Kaegi, A. Ulrich, B. Sinnet et al., "Synthetic $\mathrm{TiO}_{2}$ nanoparticle emission from exterior facades into the aquatic environment," Environmental Pollution, vol. 156, no. 2, pp. 233-239, 2008.

[36] W. Wohlleben, M. W. Meier, S. Vogel et al., "Elastic CNTpolyurethane nanocomposite: synthesis, performance and assessment of fragments released during use," Nanoscale, vol. 5, pp. 369-380, 2013.

[37] L.-Y. Hsu and H.-M. Chein, "Evaluation of nanoparticle emission for $\mathrm{TiO}_{2}$ nanopowder coating materials," Journal of Nanoparticle Research, vol. 9, no. 1, pp. 157-163, 2007.
[38] S. Sachse, F. Silva, H. Zhu, A. Irfan, A. Leszczynska, and K. Pielichowski, "The effect of nanoclay on dust generation during drilling process of polyamide 6 nanocomposites," Nanomaterials, vol. 2012, Article ID 189386, 8 pages, 2012.

[39] D. Gohler, M. Stintz, L. Hillemann, and M. Vorbau, "Characterization of Nanoparticle release from surface coatings by the simulation of a sanding process," Annals of Occupational Hygiene, vol. 54, pp. 615-624, 2010.

[40] M. Morgeneyer, O. Le Bihan, A. Ustache, and O. AguerreChariol, "Experimental study of the aerosolization of fine alumina particles from bulk by a vortex shaker," Powder Technology, vol. 246, pp. 583-589, 2013.

[41] N. Isbaseta and B. Biscans, "Ultrafine aerosol emission from free fall of $\mathrm{TiO}_{2}$ and $\mathrm{SiO}_{2}$ Nanopowders," Kona, vol. 25, pp. 190-204, 2007.

[42] P. A. Baron, A. D. Maynard, and M. Foley, "Evaluation of Aerosol Release during the handling of Unrefined Single Walled Carbon Nanotube Material," NIOSH DART-02-191, 2003.

[43] A. D. Maynard, P. A. Baron, M. Foley, A. A. Shvedova, E. R. Kisin, and V. Castranova, "Exposure to carbon nanotube material: aerosol release during the handling of unrefined single-walled carbon nanotube material," Journal of Toxicology and Environmental Health A, vol. 67, no. 1, pp. 87-107, 2004.

[44] I. Ogura, H. Sakurai, and M. Gamo, "Dustiness testing of engineered nanomaterials," Journal of Physics, vol. 170, Article ID 012003, 2009.

[45] S. Plitzko, E. Gierke, N. Dziurowitz, and D. Brobell, "Generation of CNT/CNF dusts by a shaker aerosol generator in combination with a thermal precipitator as the collection system for characterization of the fibre morphology," Gefahrstoffe Reinhaltung der Luft, vol. 70, no. 1-2, pp. 31-35, 2010.

[46] T. A. J. Kuhlbusch, C. Asbach, H. Fissan, D. Göhler, and M. Stintz, "Nanoparticle exposure at nanotechnology workplaces: a review," Particle and Fibre Toxicology, vol. 8, article 22, 2011.

[47] A. Thorpe and R. C. Brown, "Measurements of the effectiveness of dust extraction systems of hand sanders used on wood," Annals of Occupational Hygiene, vol. 38, no. 3, pp. 279-302, 1994.

[48] O. Le Bihan, M. Morgeneyer, N. Shandilya, O. A. Chariol, and C. Bressot, Handbook on Safe Use of Nanomaterials Chapter 7.2: Emission Chambers, A Method for Nanosafety, Academic Press, San Diego, Calif, USA, 2014.

[49] B. R'mili, O. Le Bihan, C. Dutouquet, O. Aguerre-Charriol, and E. Frejafon, "Particle sampling by TEM grid filtration," Aerosol Science and Technology, vol. 47, pp. 767-775.

[50] M. George and D. T. Goddard, "The characterisation of rough particle contacts by atomic force microscopy," Journal of Colloid and Interface Science, vol. 299, no. 2, pp. 665-672, 2006.

[51] J. Drelich, "Adhesion forces measured between particles and substrates with nano-roughness," Minerals and Metallurgical Processing, vol. 23, no. 4, pp. 226-232, 2006.

[52] M. S. Esayanur, S. B. Yeruva, Y. I. Rabinovich, and B. M. Moudgil, "Interaction force measurements using atomic force microscopy for characterization and control of adhesion, dispersion and lubrication in particulate systems," Journal of Adhesion Science and Technology, vol. 19, no. 8, pp. 611-626, 2005.

[53] L. J. Jallo, Y. Chen, J. Bowen, F. Etzler, and R. Dave, "Prediction of inter-particle adhesion force from surface energy and surface roughness," Journal of Adhesion Science and Technology, vol. 25, no. 4-5, pp. 367-384, 2011. 
[54] W. Q. Ding, "Micro/nano-particle manipulation and adhesion studies," Adhesion Science and Technology, vol. 22, pp. 457-480, 2008.

[55] C. Yuan, Z. Jin, J. L. Tipper, and X. Yan, "Numerical surface characterization of wear debris from artificial joints using atomic force microscopy," Chinese Science Bulletin, vol. 54, no. 24, pp. 4583-4588, 2010.

[56] A. Haris, T. Adachi, and W. Araki, "Nano-scale characterization of fracture surfaces of blended epoxy resins related to fracture properties," Materials Science and Engineering A, vol. 496, no. 1-2, pp. 337-344, 2008.

[57] S. Turri, L. Torlaj, F. Piccinini, and M. Levi, "Abrasion and nanoscratch in nanostructured epoxy coatings," Journal of Applied Polymer Science, vol. 118, no. 3, pp. 1720-1727, 2010.

[58] K. Degiampietro and R. Colaço, "Nanoabrasive wear induced by an AFM diamond tip on stainless steel," Wear, vol. 263, no. 7-12, pp. 1579-1584, 2007.

[59] M. Munz, J.-H. Kim, O. Krause, and D. Roy, "Imaging surfaces of nano-scale roughness by atomic force microscopy with carbon nanotubes as tips: a comparative study," Surface and Interface Analysis, vol. 43, no. 11, pp. 1382-1391, 2011.

[60] R. Holm, Electrical Contacts, H. Gerbers, Stockholm, Sweden, 1946.

[61] T. O. Mulhearn and L. E. Samuels, "The abrasion of metals: a model of the process," Wear, vol. 5, no. 6, pp. 478-498, 1962.

[62] E. Rabinowicz, Friction and Wear of Materials, John Wiley and Sons, New York, NY, USA, 1965.

[63] B. R. Lawn, "A model for the wear of brittle solids under fixed abrasive conditions," Wear, vol. 33, no. 2, pp. 369-372, 1975.

[64] G. Sundararajan, "A new model for two-body abrasive wear based on the localization of plastic deformation," Wear, vol. 117, no. 1, pp. 1-35, 1987.

[65] A. A. Torrance and T. R. Buckley, "A slip-line field model of abrasive wear," Wear, vol. 196, no. 1-2, pp. 35-45, 1996.

[66] U. Olofsson, "Cyclic micro-slip under unlubricated conditions," Tribology International, vol. 28, no. 4, pp. 207-217, 1995.

[67] J. Jiang, F. Sheng, and F. Ren, "Modelling of two-body abrasive wear under multiple contact conditions," Wear, vol. 217, no. 1, pp. 35-45, 1998.

[68] L. Fang, J. Xing, W. Liu, Q. Xue, G. Wu, and X. Zhang, "Computer simulation of two-body abrasion processes," Wear, vol. 250-251, no. 2, pp. 1356-1360, 2001.

[69] S. Fouvry, T. Liskiewicz, P. Kapsa, S. Hannel, and E. Sauger, "An energy description of wear mechanisms and its applications to oscillating sliding contacts," Wear, vol. 255, no. 1-6, pp. 287-298, 2003.

[70] A. A. Torrance, "Modelling abrasive wear," Wear, vol. 258, no. 1-4, pp. 281-293, 2005.

[71] M. T. Siniawski, S. J. Harris, and Q. Wang, "A universal wear law for abrasion," Wear, vol. 262, no. 7-8, pp. 883-888, 2007.

[72] K. De Moerlooze, F. Al-Bender, and H. Van Brussel, "A novel energy-based generic wear model at the asperity level," Wear, vol. 270, no. 11-12, pp. 760-770, 2011.

[73] M. Eriten, A. A. Polycarpou, and L. A. Bergman, "Physicsbased modeling for partial slip behavior of spherical contacts," International Journal of Solids and Structures, vol. 47, no. 18-19, pp. 2554-2567, 2010.

[74] M. Eriten, A. A. Polycarpou, and L. A. Bergman, "Physics-based modeling for fretting behavior of nominally flat rough surfaces," International Journal of Solids and Structures, vol. 48, no. 10, pp. 1436-1450, 2011.
[75] M. Kato, A. Tsuruta, S. Kuroda, and Z. Osawa, "Effect of stereoregularity on the photo-oxidative degradation and weathering of polypropylenes," Polymer Degradation and Stability, vol. 67, no. 1, pp. 1-5, 2000.

[76] M. L. Castejon, P. Tiemblo, and J. M. Gomez-Elvira, "Physicochemical processes along the early stages of the thermal degradation of isotactic polypropylene," Polymer Degradation and Stability, vol. 70, pp. 297-302, 2000.

[77] J. Li, R. Yang, J. Yu, and Y. Liu, "Natural photo-aging degradation of polypropylene nanocomposites," Polymer Degradation and Stability, vol. 93, no. 1, pp. 84-89, 2008.

[78] E. Schütz, F. Berger, O. Dirckx, and A. Chambaudet, "Study of degradation mechanisms of a paint coating during an artificial aging test," Polymer Degradation and Stability, vol. 65, no. 1, pp. 123-130, 1999. 

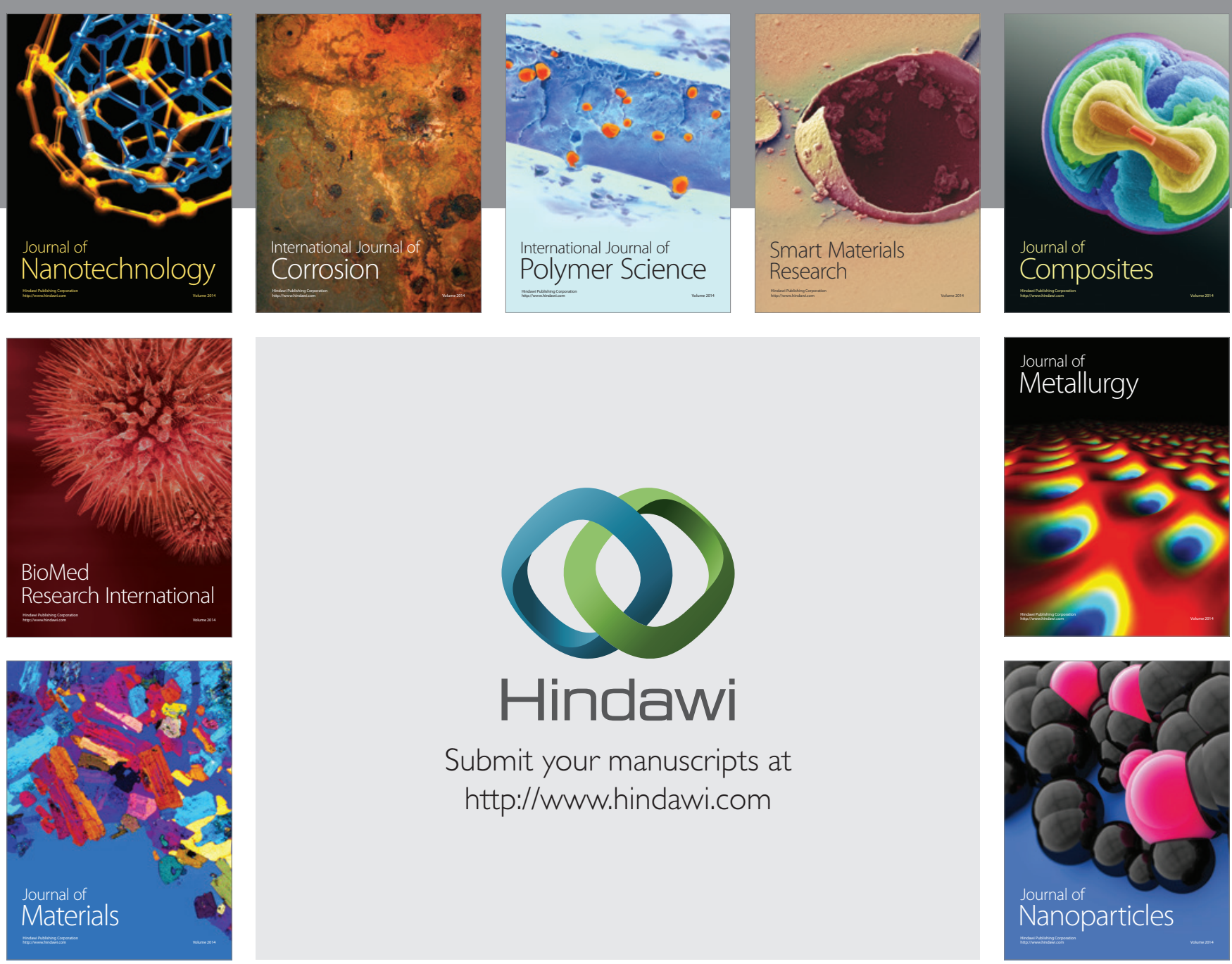

Submit your manuscripts at http://www.hindawi.com


\section{The Scientific World Journal}
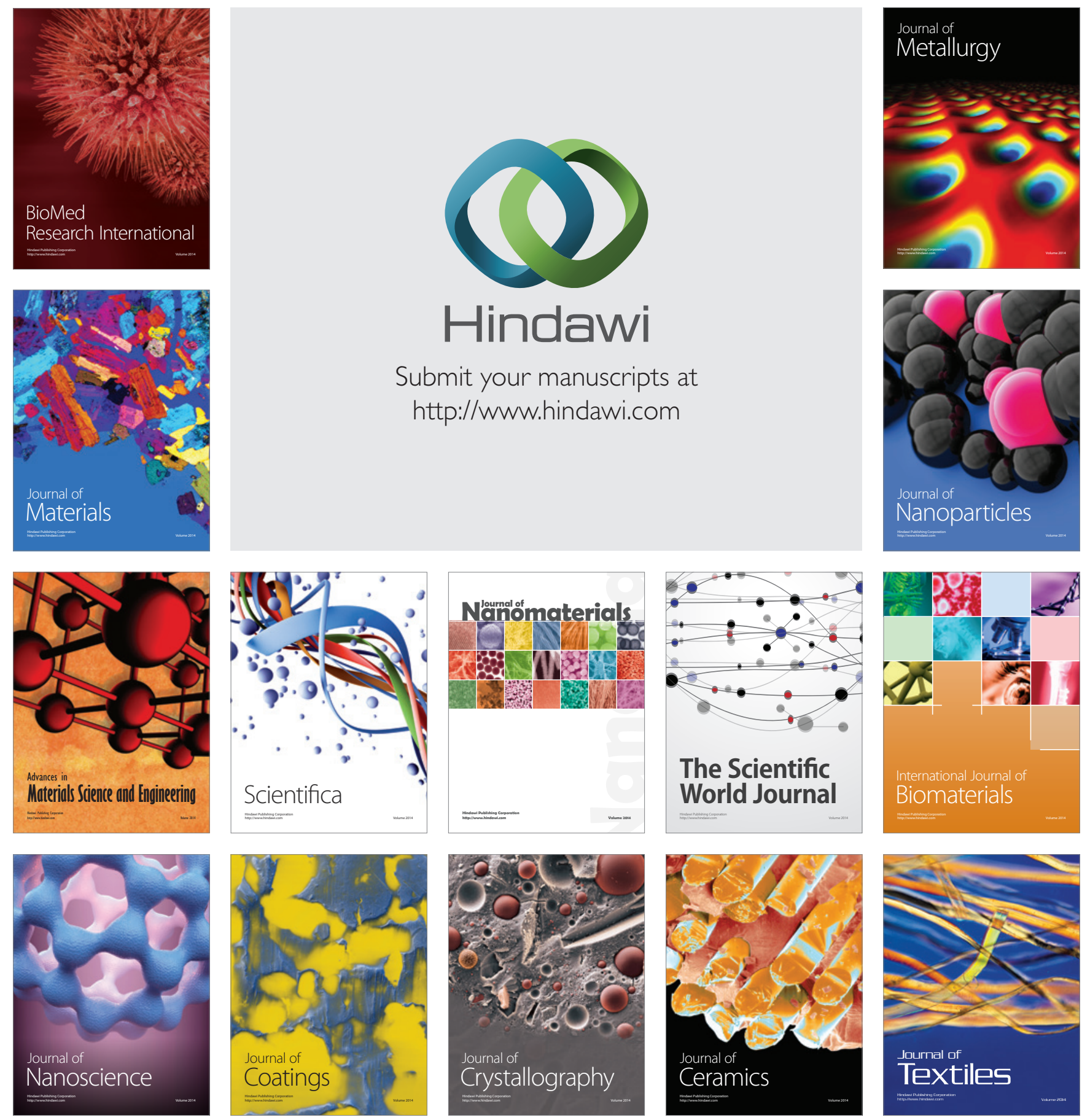